Supplement of Geosci. Model Dev., 13, 1685-1710, 2020

https://doi.org/10.5194/gmd-13-1685-2020-supplement

(C) Author(s) 2020. This work is distributed under

the Creative Commons Attribution 4.0 License.

(c) (1)

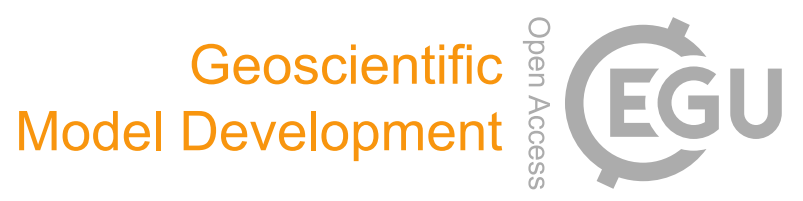

Supplement of

\title{
COSMO-BEP-Tree v1.0: a coupled urban climate model with explicit representation of street trees
}

\section{Gianluca Mussetti et al.}

Correspondence to: Dominik Brunner (dominik.brunner@empa.ch) and Gianluca Mussetti (mussetti.gianluca@gmail.com)

The copyright of individual parts of the supplement might differ from the CC BY 4.0 License. 


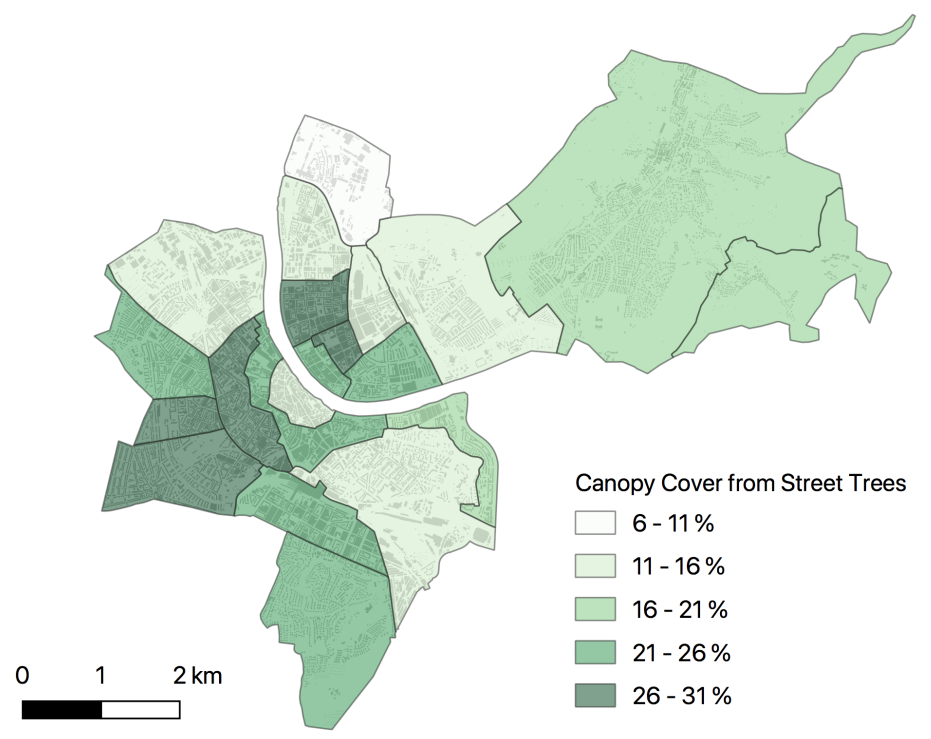

Figure S1. Canopy cover from street trees in the administrative districts of Basel-Stadt (Geoportal Kanton Basel-Stadt, 2019). Building geometries are shown in the background (Federal Office of Topography, 2007).

Table S1. Number and percentage of the 10 most common tree species found as public street tree in the inner part of Basel. The data are derived from the inventory of urban trees of the city of Basel (Geoportal Kanton Basel-Stadt, 2019).

\begin{tabular}{lcccc}
\hline Species & Num. & $\%$ & \multicolumn{2}{c}{$g_{s}\left[\mathrm{mmol} \mathrm{m}^{-2} \mathrm{~s}^{-1}\right]$} \\
& & & night & day \\
\hline Tilia x euchlora (Caucasian lime) & 3433 & 11.3 & $20^{a}$ & $100^{a}$ \\
Platanus x hispanica (London plane) & 2766 & 9.1 & $18^{b}$ & $180^{b}$ \\
Aesculus hippocastanum (Horse-chestnut) & 2083 & 6.9 & 20 & 90 \\
Acer platanoides (Norway maple) & 1495 & 4.9 & 18 & 180 \\
Tilia cordata (Small-leaved lime) & 990 & 3.3 & $20^{a}$ & $100^{a}$ \\
Carpinus betulus (Common hornbeam) & 903 & 3.0 & $20^{c}$ & $100^{c}$ \\
Acer campestre (Field maple) & 851 & 2.8 & $18^{b}$ & $180^{b}$ \\
Pinus sylvestris (Scots pine) & 682 & 2.3 & $17^{d}$ & $330^{d}$ \\
Quercus robur (Common oak) & 671 & 2.2 & 22 & 210 \\
Taxus baccata (Common yew) & 651 & 2.1 & $15^{e}$ & $80^{e}$ \\
Average $f$ & & & 19 & 142 \\
\hline
\end{tabular}

${ }^{a}$ values of Tilia europaea. ${ }^{b}$ values of Acer platanoides. ${ }^{c}$ from Keel et al. (2007) Fig. 2 year 2003. For night-time, the value from Tilia europaea are used. ${ }^{d}$ from Campbell and Norman (2012) Table 7.2 values for Pinus monticola. ${ }^{e}$ from Xiong et al. (2018) Fig. $2 .{ }^{f}$ weighted with the corresponding $\%$ of trees within the sample. 


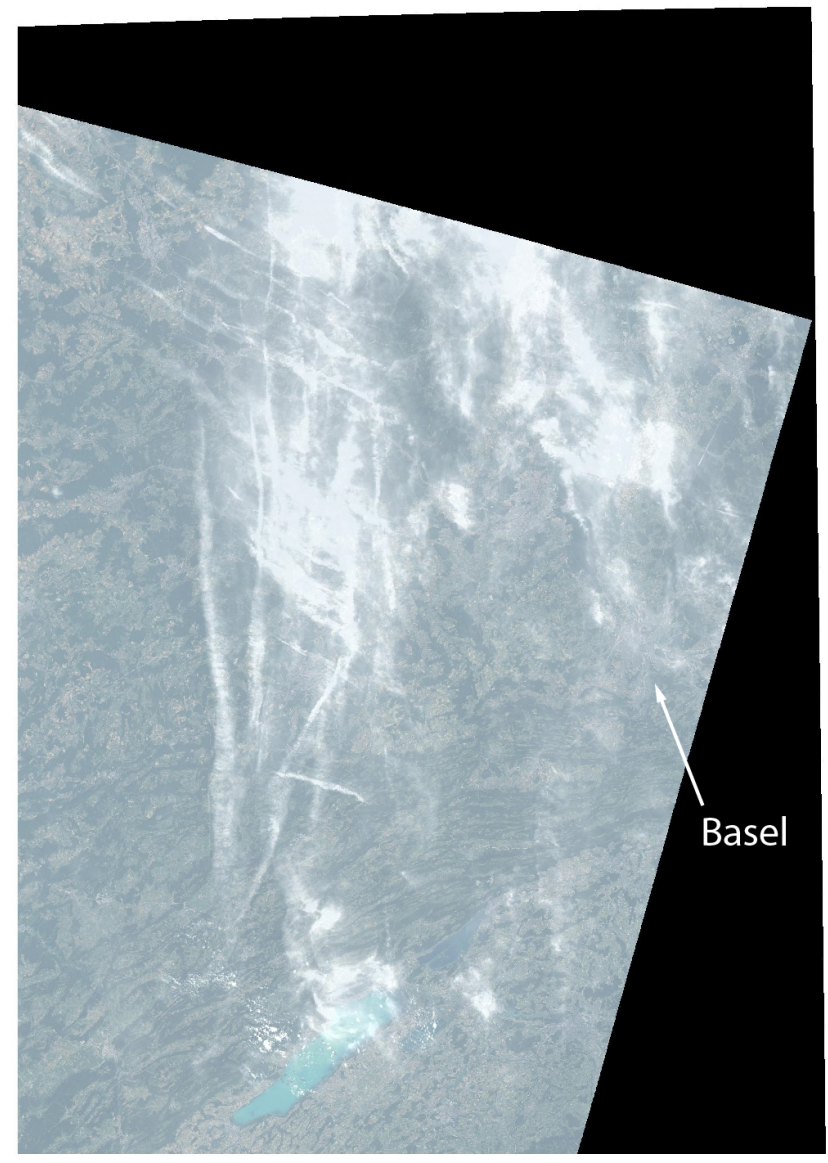

Figure S2. Cirrus clouds above the model domain detected from the cirrus band (Band 9) of Landsat 8 satellite during the overpass of 4 July 2015 .

Table S2. Root-mean-square errors (RMSE), mean-bias errors (MBE) and coefficient of determination $\left(r^{2}\right)$ of the observed air temperatures $\left(T_{\text {air }}\right)$, specific humidity $(q)$, and wind speed $(\mathbf{u})$ at the rural site of BLER (10 m above ground) during the period 22 June $2015-9$ July 2015 (discarding the first 5 days as spin-up). In addition to the total RMSEs (T), the systematic (S) and the unsystematic (U) RMSEs are listed. The statistics are provided for the standard simulation (STD) only.

\begin{tabular}{l|ccc}
\hline & RMSE (T/S/U) & MBE & $r^{2}$ \\
\hline$T_{\text {air }}(K)$ & $1.74 / 1.34 / 1.10$ & 1.34 & 0.96 \\
$q\left(g \mathrm{~kg}^{-1}\right)$ & $1.33 / 0.60 / 1.19$ & -0.56 & 0.65 \\
$u\left(m s^{-1}\right)$ & $1.32 / 0.43 / 1.25$ & 0.41 & 0.32 \\
\hline
\end{tabular}


(a)

E1 (Sobrino et al., 2008)

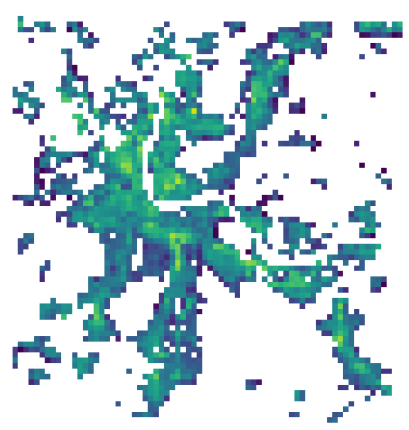

(b)

E2 (Loridan and Grimmond, 2012)

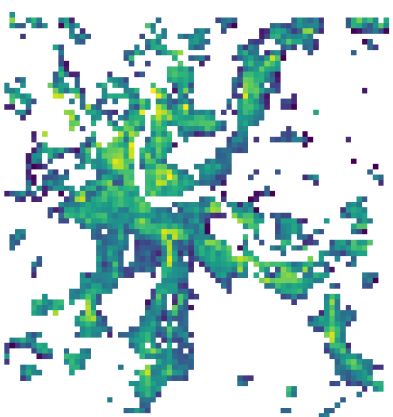

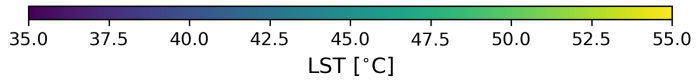

(c)

$\mathrm{E} 2-\mathrm{E} 1($ mean $=1.25)$

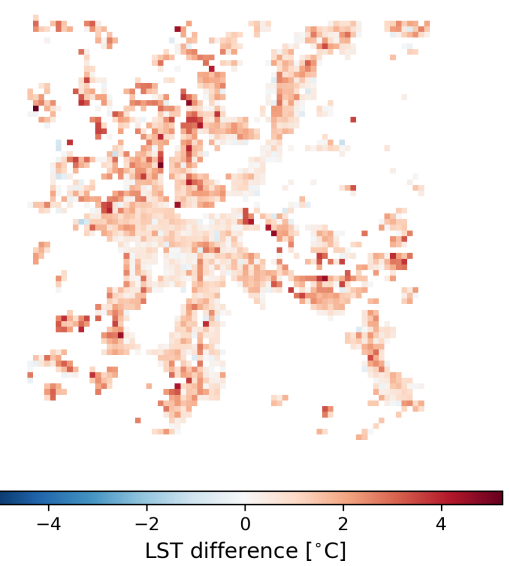

Figure S3. Impact of the choice of emissivity values for urban surfaces on the land surface temperature (LST). (a,b) show the observed LST with emissivity values from Sobrino et al. (2008) and Loridan and Grimmond (2012), respectively; (c) shows the difference in LST between the two approaches. 

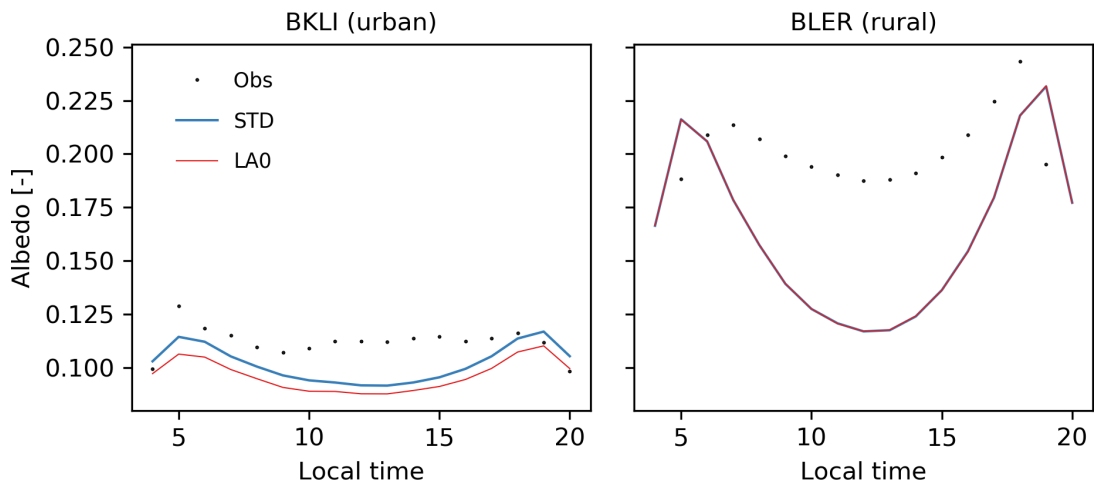

Figure S4. Average diurnal profile of observed (Obs) and modelled (STD, LA0) albedo. Albedo is calculated as the ratio between upward and downward short-wave radiation. The site BKLI is characterised by an urban fraction ( $f_{u r b}$ ) of 0.79 .
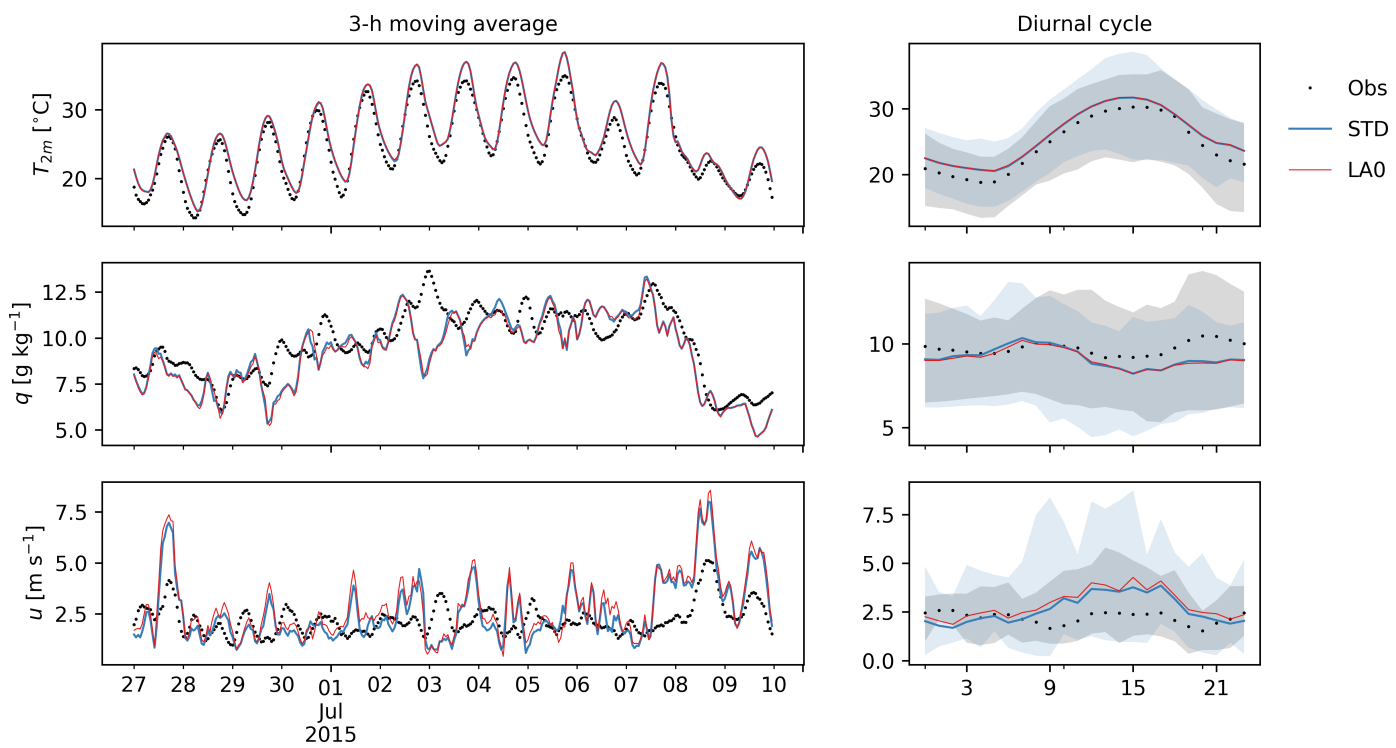

Figure S5. Comparison between observations (Obs) and model simulations of air temperature (a), specific humidity (b), wind speed (c), sensible heat flux (d) and latent heat flux (e) at the rural reference site BLER (10 m above ground) during the selected period (discarding the first 5 days as spin-up). Blue lines and red lines indicate the results from the STD and LAD0 model set-ups, respectively. The shaded areas represent the range of variability within the period for the observations and STD simulation only. 

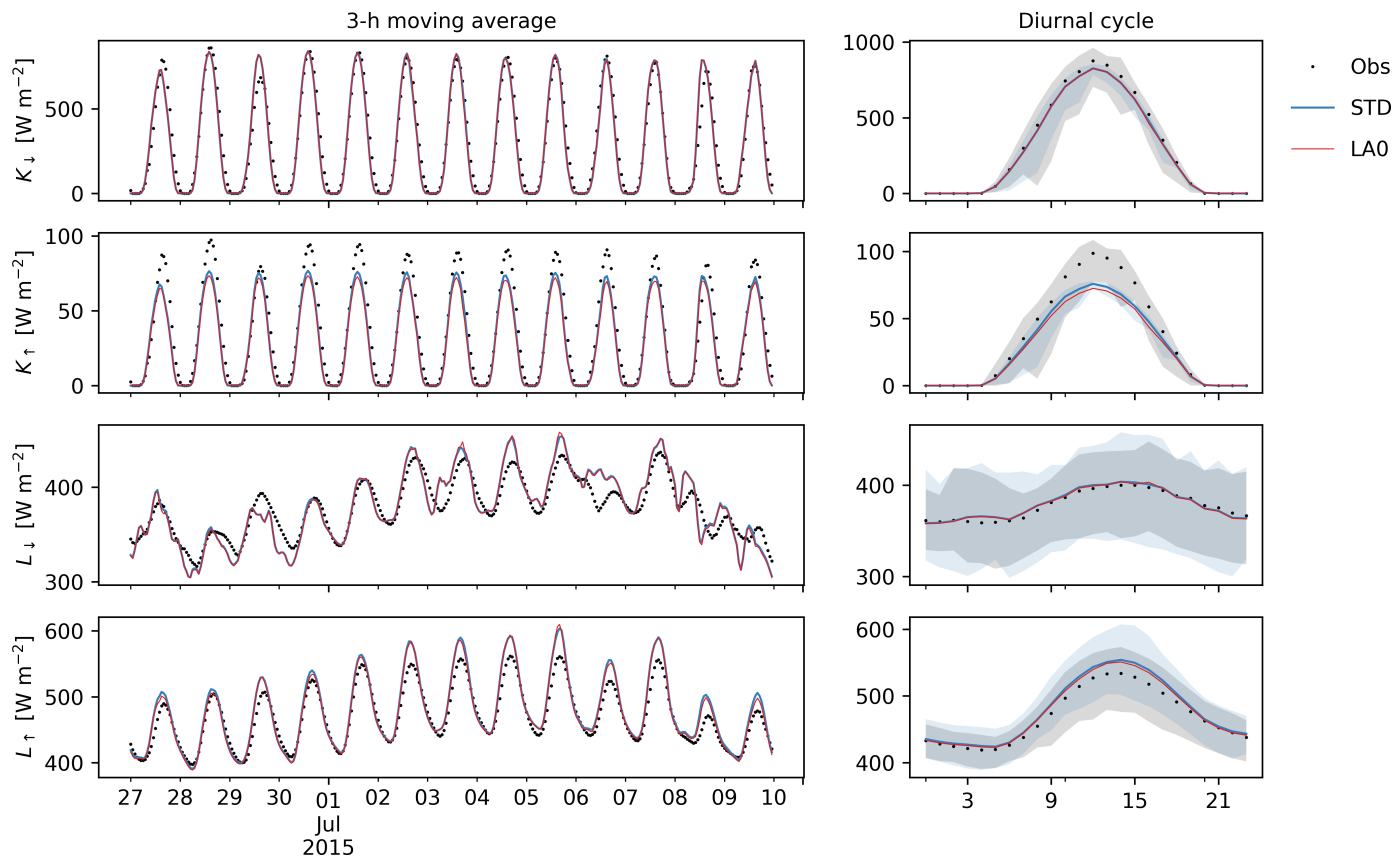

Figure S6. Comparison between observations (Obs) and model simulations of downward short-wave radiation $K_{\downarrow}$ (a), upward short-wave radiation $K_{\uparrow}$ (b), downward long-wave radiation $L_{\downarrow}$ (c) and upward long-wave radiation $L_{\uparrow}(\mathrm{d})$ at the site of BKLI during the selected period (discarding the first 5 days as spin-up). Blue lines and red lines indicate the results from the STD and LAD0 model set-ups, respectively. The shaded areas represent the range of variability within the period for the observations and STD simulation only.

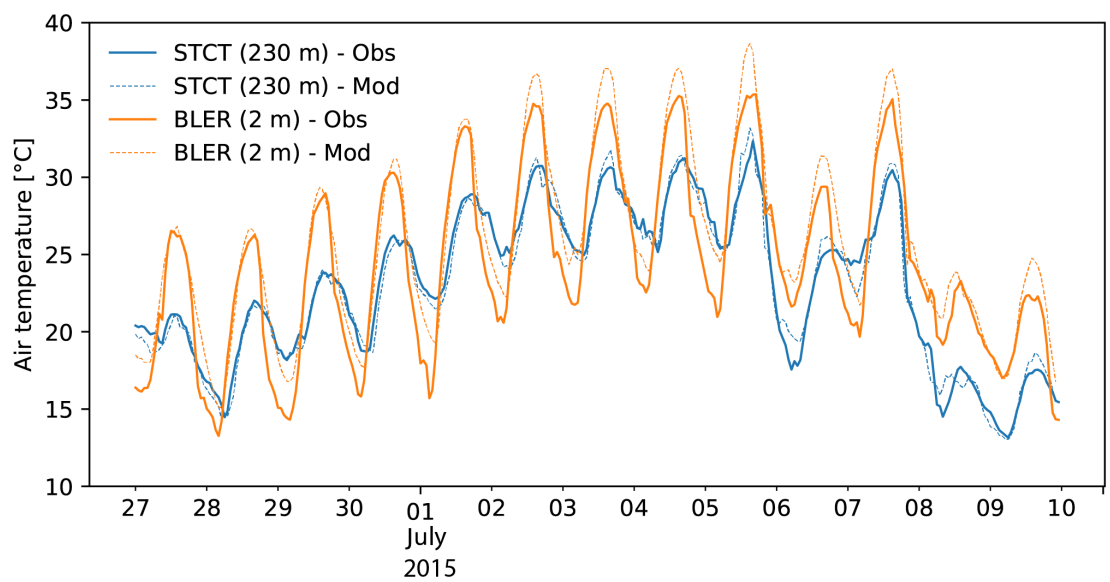

Figure S7. Air temperature evolution at the sites of St. Chrischona (STCT, $230 \mathrm{~m}$ a.g., lat=47.571767, lon=7.687094) and BLER (2 m a.g.). Solid and dashed lines indicate observations (Obs) and model simulation (Mod), respectively. The evolution suggests the formation of a stable boundary layers (characterised by a strong temperature inversion) during the nights in central part of the period. 


\section{References}

Campbell, G. S. and Norman, J. M.: An introduction to environmental biophysics, Springer Science \& Business Media, 2012.

Federal Office of Topography, S. C.: swissBUILDINGS3D 1.0, https://shop.swisstopo.admin.ch/en/products/landscape/build3D, 2007.

Geoportal Kanton Basel-Stadt: https://www.geo.bs.ch/, 2019.

5 Keel, S. G., Pepin, S., Leuzinger, S., and Körner, C.: Stomatal conductance in mature deciduous forest trees exposed to elevated CO 2 , Trees, 21, 151, https://doi.org/10.1007/s00468-006-0106-y, 2007.

Loridan, T. and Grimmond, C.: Multi-site evaluation of an urban land-surface model: intra-urban heterogeneity, seasonality and parameter complexity requirements, Quarterly Journal of the Royal Meteorological Society, 138, 1094-1113, https://doi.org/10.1002/qj.963, 2012.

Sobrino, J. A., Jiménez-Muñoz, J. C., Sòria, G., Romaguera, M., Guanter, L., Moreno, J., Plaza, A., and Martínez, P.: Land surface emissivity retrieval from different VNIR and TIR sensors, IEEE Transactions on Geoscience and Remote Sensing, 46, 316-327, https://doi.org/10.1109/TGRS.2007.904834, 2008.

Xiong, D., Douthe, C., and Flexas, J.: Differential coordination of stomatal conductance, mesophyll conductance, and leaf hydraulic conductance in response to changing light across species, Plant, cell \& environment, 41, 436-450, https://doi.org/10.1111/pce.13111, 2018. 